ХИМЕРНАЯ НОВИЗНА ПОЛУЧЕННЫХ РЕЗУЛЬТАТОВ ИССЛЕДОВАНИЯ ОБ АЭРОПОРТАХ МВЛ

\author{
Леонтьев Рудольф Георгиевич \\ $\partial-р$ экон. наук, профессор, \\ почетный работник высшего профессионального образования РФ, \\ главный научный сотрудник ВЦ ДВО РАН, \\ 2. Хабаровск, Российская Федераџия
}

\title{
CHIMERIC NOVELTY OF THE OBTAINED RESULTS RESEARCH ABOUT MVL AIRPORTS
}

В статье рассмотрена представленная в отзыве ведущей организации нелепая попытка его продуцентов раскрыть химерную новизну полученных результатов, выводов и рекомендаций диссертации о менеджменте аэропортами местных воздушных линий. Доказано, что эта попытка сотрудников МИИТ вызвана их халатным незнанием текста диссертации, а еe (попытки) результатом стала фальсифицированное (то есть на самом деле несуществующее в действительности) содержимое этой научно-квалификационной работы.

\section{ANNOTATION}

The article considers the absurd attempt of its producers presented in the review of the leading organization to reveal the chimeric novelty of the results, conclusions and recommendations of the dissertation on the management of local airlines. It is proved that this attempt of MIIT employees was caused by their negligent ignorance of the text of the dissertation, and its (attempts) resulted in a falsified (that is, in fact, non-existent in reality) content of this scientific qualification work.

Ключевые слова: Менеджмент аэропортами, местные воздушные линии (МВЛ), государственная научная аттестация, диссертация, отзыв ведущей организации, новизна полученных результатов, выводов и рекомендаций диссертации.

Key words: Airport management, local airlines (MVL), state scientific attestation, dissertation, feedback from a leading organization, novelty of the results obtained, conclusions and recommendations of the dissertation.

Между невежеством и знанием лежит пропасть.

Японская пословица

Известно, что в соответствии с пунктом 23 (абзац 1) действующего на момент защиты диссертации Милой "Положения о порядке присуждения ученых степеней”, утвержденного постановлением правительства РФ от 30 января 2002 года № 74 (в редакции постановления правительства РФ от 20 июня 2011 года № 475) (далее - «Положение о порядке присуждения ученых степеней!), «диссертационные советы назначают по диссертациям ведущие (оппонирующие) организации, «известные своими достижениями в соответствующей отрасли науки».

Однако, «диссертационный совет ДМ 223.005.02 при Морском государственном университете им. адм. Г.И. Невельского» по диссертации Милой назначил ведущей организацией «Московский государственный университет путей сообщения (МИИТ)», который практически неизвестен своими достижениями в научной сфере гражданской авиации. Во всяком случае, в 2012 году не были известны изданные под эгидой данного вуза "ваковские" и обычные научные публикации в этой же сфере.
Поэтому МИИТ, как и его сотрудники, поставившие свои подписи на отзыве этой ведущей организации, в 2012 году не были достаточно «известными своими достижениями в научной сфере гражданской авиации (воздушного транспорта)». При этом, забегая вперед, следует отметить, что именно эта причина, не в последнюю очередь, предопределила отвратительно неприемлемое качество содержания упомянутого отзыва на пресловутое «диссертационное исследование» соискателя ДВГУПС Милой.

В силу вышеизложенного представляется необходимым детально рассмотреть содержание представленного МИИТ отзыва ведущей организации, конкретные впечатления о котором могут охарактеризовать приведенные в настоящей работе ниже следующие негативные обстоятельства.

Для начала следует отметить, что в соответствии с пунктом 23 (абзацы 2 и 3 ) «Положения о порядке присуждения ученых степеней», «в отзыве ведущеей организации отражается значимость полученных автором диссертации результатов», а «в отзыве о работах имеющих прикладной характер, должны также содержаться конкретные рекомендаџии по использованию результатов и выводов диссертации». 
Итак, в «диссертационный совет ДМ 223.005 .02 при Морском государственном университете им. адм. Г.И. Невельского» поступил «Отзыв ведущей организации федерального государственного бюджетного образовательного учреждения высшего профессионального образования «Московский государственный университет путей сообщения» на диссертацию Милой А. В. «Управление инфраструктурой аэропортов малой интенсивности полетов», представленную к защите на соискание ученой степени кандидата экономических наук по специальности 08.00.05 - «Экономика и управление народным хозяйством (экономика, организация и управление предприятиями, отраслями, комплексами: транспорт)».

Этот документ государственной научной аттестации утвердил «и. о. проректора по научной работе, д.т.н., профессор Саврухин А.В.» (в данной расшифровке утверждающей подписи после слова «работе» следовало отобразить, хотя бы, аббревиатуру «МИИТ», поэтому здесь налицо недопустимая ошибка в оформлении отзыва ведущей организации), а подписали его «зав. кафедрой «Транспортный бизнес», доцент» С.В. Абрамов и предполагаемый инициатор-продуцент подготовки данного «отзыва» - заместитель директора Института управления и информационных технологий (ИУИТ) по научной работе Московского государственного университета путей сообщения, профессор кафедры «Транспортный бизнес», доктор экономических наук, профессор» П.В. Куренков.

Указанный отзыв содержит следующие разделы: «Общая характеристика диссертационной работы»; «Актуальность и значимость для науки и производства полученных автором диссертации результатов»; «Новизна исследований и полученных результатов, выводов и рекомендаций, сформулированных в диссертации»; «Наиболее значимые для науки и производства, полученные соискателем результаты»; «Конкретные рекомендации по использованию результатов и выводов диссертации»; «Замечания и недостатки»; «Оценка диссертации в целом».

Уже относительно названия (заголовка) третьего раздела отзыва ведущей организации МИИТ «Новизна исследования и полученных результатов, выводов и рекомендаций, сформулированных в диссертации» можно выявить следующие негативные обстоятельства:

- во-первых, заголовок третьего раздела «отзыва ведущей организации представлен с нарушением правил построения русской фразеологии. В данном случае достаточно корректно заголовок должен был изложен следующим образом: «Новизна полученных автором диссертации результатов $u$ сформулированных в ней выводов и рекомендаций»;

- во-вторых, если уже и отражать «новизну полученных в диссертации результатов», а также «новизну научных положений выводов и рекомендаций, сформулированных в диссертации», то в соответствии с пунктом 12 (абзац 1) «Положения о порядке присуждения ученых степеней» ее следует изложить после отражения «степени достоверности» этих же «результатов», а также согласно пункту 22 (абзац 1) данного «Положения...» - после «оценки степени обоснованности» этих же «научных положений выводов и рекомендаций, сформулированных в диссертации». А не так, как это безалаберно делают Куренков и др. в «отзыве ведущей организации сначала во втором разделе «отражают значимость полученных автором диссертации результатов», затем в третьем разделе «отзыва» пытаются «оценивать» их «новизну» и только потом в четвертом разделе «отзыва» приводят конкретное содержание самих «полученных автором диссертации результатов». Хотя все это надо было сделать наоборот (в обратном порядке). Налицо - первый факт незнания или преднамеренного игнорирования сотрудниками МИИТ Куренковым и др. положений основного документа государственной научной аттестации;

- в-третьих, в соответствии с пунктом 23 (абзац

2) «Положения о порядке присуждения ученых степеней» «в отзыве ведущей организации отражается значимость полученных автором диссертации результатов», а «в отзыве о работах, имеющих прикладной характер, должны содержаться рекомендации по использованию результатов и выводов диссертации». Поэтому вопреки сформулированному заголовку третьего раздела соответствующего документа Куренкова и др. в отзыве ведущей организации, с одной стороны, официально не предписывается «отражать новизну» ни «исследования», ни «полученных результатов», ни «выводов и рекомендаций, сформулированных в диссертации». A, с другой стороны, вместо «новизны рекомендаций, сформулированных в диссертации», в «отзыве ведущей организации» МИИТ Куренков и др. должны были отразить «рекомендации по использованию результатов и выводов диссертации» Милой. Налицо - второй факт незнания или преднамеренного игнорирования сотрудниками МИИТ Куренковым и др. положений основного документа государственной научной аттестации.

Третий раздел «отзыва ведущей организации» МИИТ (Куренков и др.) представлен одним абзацем, изложенным в виде единственного сложного предложения следующим образом:

«Научная новизна проведённого исследования заключается в следующем:

- уточнено и расширено содержание понятия «аэропортовая инфраструктура», позволяющее выделить и рассматривать инфраструктуру аэропорта в современных условиях трансформации экономики государства как самостоятельный вид бизнеса;

- обосновано использование механизма ГЧП в управлении инфраструктурой аэропортов малой интенсивности полётов, как особого взаимовыгодного добровольного альянса между 
государством и бизнесом для реализации общественно значимых целей, в котором одна сторона (государство) преследует, прежде всего, некоммерческие цели, а вторая (бизнес) действует в целях извлечения прибыли;

- предложены вариант экономической структуры предприятия (как системы взаимодействия финансовых потоков и функций управления) и показатели эффективности и результативности создания ГЧП для управления инфраструктурой в аэропортах малой интенсивности полётов на основе разделения неавиационной аэропортовой деятельности на основную и вспомогательную, что позволяет повысить эффективность их работы и более полно учесть интересы государства и бизнеса».

Анализ содержания единственного абзаца (сложного предложения) третьего раздела «отзыва ведущей организации» МИИТ (Куренков и др.) позволяет выявить следующие негативные обстоятельства:

a) как уже было отмечено в монографии $[1, \mathrm{c}$ 159], в первом разделе автореферата «Общая характеристика диссертации» (стр. 6,7) и во введении диссертации Милой (стр. 9,10) вслед за подразделом «основные результаты исследования» этот соискатель ДВГУПС представил подраздел «научная новизна проведенного исследования». При этом сообщается, что пункты подраздела «научная новизна проведенного исследования» представлены также и во втором разделе автореферата Милой (с. 8-21), но уже как «основные положения, выносимые на защиту». И поэтому в монографии [1] указанные пункты не рассматривались, поскольку раскрытие их сущности, свойственной и «основным положениям, выносимым на защиту» в диссертации Милой, стало предметом другой публикации (монографии) [2];

б) вместе с тем, содержание третьего раздела «отзыва ведущей организации» Куренков и др. с абсолютной точностью скопировали (то есть, как говорится, «ни прибавить, ни убавить») с текста подраздела «научная новизна проведенного исследования», представленного в автореферате (стр. 6,7) и во введении диссертации Милой (стр. 9,10). И тем самым эти сотрудники МИИТ безоговорочно подписались под «научной новизной проведенного исследования», сформулированной не только виде соответствующих пунктов «новизны» пресловутой диссертации Милой, но и в качестве «основных положений, выносимых на защиту», как это утверждается в ее автореферате (стр. 8-21). При этом Куренков и др. даже не представляли себе, насколько это чревато для их научно-общественной репутации. Ведь такое безалаберное действие означает то, что указанные сотрудники МИИТ решили не «заморачиваться» самостоятельной оценкой всех трех пунктов «новизны научных положений...» Милой и предпочли схалтурить, воспользовавшись еe, как оказалось, безграмотными формулировками. Это, в свою очередь, означает только то, что Куренков и др., в силу своего невежества безалаберно приняли на себя все огрехи этих пресловутых оценочных формулировок. А, зря...;

в) так, относительно представленного в третьем разделе «отзыва ведущей организации» первого пункта «научной новизны проведенного исследования» (первого «основного положения, выносимых на защиту») из диссертации Милой можно отметить следующие негативные обстоятельства:

- во-первых, в данном разделе Куренков и др. утверждают о том, что в диссертации Милой, якобы, «уточнено и расширено понятие «аэропортовая инфраструктура...». Однако, как уже сообщалось в настоящей монографии выше, сами же Куренков и др., очевидно, неосознанно опровергают это утверждение, поскольку на стр. 7 (в разделе «Замечания и недостатки») «отзыва ведущей организации» отмечают, что «в первой главе... ясное авторское определение «инфраструктуры аэропортов...» не представлено». А ведь известно, что «уточнить и расширить» какое-нибудь «понятие» можно только при помощи «уточнения и расширения» именно его определения. Похоже, что у Куренкова и др. «правая рука не знает, что делает левая». Налицо очередные факты проявления незнания содержания диссертации, противоречивости собственных суждений и недостаточного представления о методологии исследования у представителей МИИТ Куренкова и др.;

- во-вторых, подробный анализ первого «выносимого на защиту основного положения диссертационного исследования» рассматривался на 58-ми страницах раздела 2 монографии [2, с. $12-$ 70], в котором, в частности, отмечалось, что уже поверхностное знакомство с формулировкой этого «положения» позволило выявить недопустимые для научных и научно-квалификационных работ случаи тривиальной неграмотности и отсутствия достаточной научной компетенции у Милой, а также необоснованность, неграмотность и неприемлемость использования этим соискателем ДВГУПС в формулировке первого «выносимого на защиту основного положения диссертационного исследования» в качестве понятия таких словосочетаний, как «аэропортовая инфраструктура» и «инфраструктура аэропорта» подтверждают следующие обстоятельства, представленные в работах [1,3-7];

- в-третьих, а в подразделе 2.2 монографии [2, c. 44-54] отмечается, что попытка соискателя ДВГУПС Милой сформулировать в автореферате (стр. 11) и в ее диссертации (стр. 22) «уточненное и расширенное определение понятия «аэропортовая инфраструктура», которое не несет никакой специфики гражданской авиации (воздушного транспорта) и которое она анонсировала в своем автореферате в качестве первого «выносимого на защиту основного положения диссертационного исследования», представляется крайне безмозглым 
и наглым деянием, являющимся типичным образчиком профанации российской науки;

- в-четвертых, там же [2, с. 44-54] отмечается, что соискатель ДВГУПС Милая со своей детской наивностью, присущей и весьма недалеким взрослым людям, не только не постеснялась попросту украсть из публикаций [8-11] и других работ формулировку «аэропорт ... необходимо рассматривать... как самостоятельный вид предпринимательской деятельности» и жульнически выдать ее за свою. Но и откровенно нагло представить на суд научной общественности практически идентичную формулировку («позволяющее выделить и рассматривать инфраструктуру аэропорта ... как самостоятельный вид бизнеса») в автореферате (стр. 6) и диссертации (стр. 9) в качестве, якобы, предложенного лично ею единственного признака первого элемента «научной новизны проведенного исследования» и, одновременно, как, якобы, первое «выносимое на защиту основное положение диссертационного исследования» (см. стр. 8 автореферата);

- в-пятых, таким образом, излагая в абзаце третьего раздела «отзыва ведущей организации» первый пункт «научной новизны проведенного исследования» диссертации» со слов Милой, сотрудники МИИТ Куренков и др. в очередной раз проявили свойственное им халтурное отношение к своим обязанностям составителей этого документа («отзыва») и свое лжесвидетельство, а также собственную постыдную некомпетентность;

г) относительно же представленного в третьем разделе «отзыва ведущей организации» второго пункта «научной новизны проведенного исследования» (второго «основного положения, выносимых на защиту») из диссертации Милой можно отметить следующие негативные обстоятельства:

- во-первых, подробный анализ второго пункта «научной новизны проведенного исследования» (второго «выносимого на защиту основного положения диссертационного исследования») Милой рассматривался на 69-ти страницах раздела 3 «Фантом «обоснования использования ГЧП» монографии [2, с. 70-138], состоящего из двух подразделов - «3.1. «Завиральная байка о «добровольном альянсе» и «3.2. «Липовые» обоснования «использования механизма ГЧП». Где, в частности, было констатировано, что уже поверхностное знакомство с формулировкой этого «положения» позволило выявить недопустимые для научных и научно-квалификационных работ случаи ужасающей безграмотности и катастрофического отсутствия научной и специальной компетенции у соискателя ДВГУПС Милой, и при этом были приведены достаточно подробные соответствующие доказательства. Вместе с тем, поскольку в «третьем подразделе «отзыва ведущей организации» Куренков и др. безалаберно воспроизвели без замечаний списанную ими из автореферата и диссертации Милой формулировку второго пункта «научной новизны проведенного исследования», то налицо соответствующие факты безграмотности и некомпетентности, присущие данным сотрудникам МИИТ;

- во-вторых, что касается фактической достоверности второго пункта «научной новизны проведенного исследования» (второго «выносимого на защиту основного положения диссертационного исследования») [2], то сформулированное в 2012 году соискателем ДВГУПС Милой (и откорректированное в монографии [2]) утверждение о том, что де только ею лично (то есть до нее достичь этого результата не удавалось даже всему мировому научному сообществу) было «обосновано использование механизма государственно-частного партнёрства в деятельности аэропортов малой интенсивности полётов», представляется нонсенсом. Доказательствами этого могут служить сформулированные в монографиях [1] и [2, с. 73-77] обстоятельства;

- в-третьих, в итоге, изложенные в монографиях [1,2] обстоятельства позволяют признать утверждение соискателя ДВГУПС Милой о том, что в качестве второго «выносимого на защиту основного положения диссертационного исследования», лично ею было «обосновано использование механизма государственночастного партнёрства в деятельности аэропортов малой интенсивности полётов», малограмотно сформулированной либо наивной несусветной глупостью, либо цинично-наглой ложью. Поскольку «обоснование использование механизма государственно-частного партнёрства в деятельности аэропортов МВЛ (и даже так называемых «аэропортов малой интенсивности полётов») была определена в РФ задолго до появления такого «фундаментально-научного труда», как пресловутая «диссертация» небезызвестного соискателя ДВГУПС Милой. Таким образом, остепененные сотрудники МИИТ Куренков и др., воспроизведя в третьем разделе «отзыва ведущей организации» формулировку второго пункта «научной новизны проведенного исследования», поневоле (не исключено, что и по воле) в очередной раз стали «компаньонами» пресловутого соискателя ДВГУПС Милой в деле плагиата (литературного воровства) и малограмотного формулирования либо наивной несусветной глупости, либо цинично-наглого вранья;

- в-четвертых, как отмечается в монографии [2, c. 78,79], остается только согласиться с утверждениями давших отрицательные отзывы на диссертацию Милой высококвалифицированных сотрудников ДВГУПС, СПбГУГА и ЦСР ГА о том, что и в этом пресловутом «исследовании» вообще отсутствует приемлемое «обоснование использования механизма государственночастного партнёрства в деятельности аэропортов малой интенсивности полётов»;

- в-пятых, указанное «псевдообоснование» предусматривало [2], «использование механизма 
ГЧП в деятельности аэропортов малой интенсивности полётов», которые, по мнению соискателя ДВГУПС Милой, должны находиться и функционировать на долгие времена только в составе КГУП «Хабаровские авиалинии», то есть так называемого «объединенного» государственного унитарного предприятия (ГУП) гражданской авиации, находящегося в собственности субъекта РФ (Хабаровского края). В состав такого типа ГУП обычно входят объединенные в одно юридическое лицо (хозяйствующий субъект) авиакомпания и аэропорты;

- в-шестых, однако [2], в ставшем предметом плагиата со стороны Милой документе Правительства Хабаровского края от 2009 года [12], в частности, говорилось следующее: «Одним из самых важных моментов в построении оптимальной современной модели аэропортов РФ является разделение авиаперевозочного и аэропортового бизнеса, объясняя это тем, что при их объединении основная доля средств вкладываются в текущий авиатранспортный бизнес, жертвуя при этом модернизацией и развитием аэропортовой инфраструктуры. Примером этого может служить компания КГУП «Хабаровские авиалинии», которая как раз построена на таком принципе объединения, что противоречит основным целям развития этих двух видов бизнеса, разных по сути, - доходы аэропорта являются затратами авиакомпании и наоборот. За сравнительно небольшой период существования компании (5 лет) убыток компании вырос практически в 5 раз, покрытие которого требует с каждым годом все больший объем краевого субсидирования». Вместе с тем, в соответствии с приложением № 3 к утвержденной приказом Минтранса России от 10 января 2007 года № 5 «Концепции управления федеральным имуществом аэропортов (аэродромов) гражданской авиации» одним из первостепенных условий «привлечения инвестиций организаций частного сектора экономики в аэропортовое имущество федеральных государственных унитарных предприятий гражданской авиации» является «разделение «объединенных» авиапредприятий на независимые хозяйствующие субъекты авиационные компании и аэропорты»;

- в-седьмых, и соискателю ДВГУПС Милой обязательно следовало бы учесть данные факты [2] и сформулировать свои суждения и доказательства ненужности разделения КГУП на «независимые хозяйствующие субъекты - авиационную компанию и аэропорты» и выявить преимущества применения ГЧП для развития аэропортов МВЛ («АМИП»), когда они остаются в составе «объединенного» КГУП «Хабаровские авиалинии». Но, к великому сожалению, Милая не сделала это ни в своей диссертации, ни в ее автореферате, что делает второй пункт «новизны проведенного исследования» недостоверным и никчемным. Налицо - очередные факты отсутствия у Куренкова и др. научной и специальной компетенции в сфере гражданской авиации;

д) относительно же представленного в третьем разделе «отзыва ведущей организации» третьего пункта «научной новизны проведенного исследования» (третьего «основного положения, выносимых на защиту») из диссертации Милой можно отметить следующие негативные обстоятельства:

- во-первых, подробный анализ третьего пункта «научной новизны проведенного исследования» (третьего «выносимого на защиту основного положения диссертационного исследования») Милой рассматривался на 72-х страницах раздела 4 «Фантом «экономической структуры предприятия» монографии [2, с. 138210], состоящего из двух подразделов - «4.1. «Завиральная байка об «эффектном разделении» и «4.2. «Фальшивая структура и «липовые показатели». Где, в частности, была приведена [2, c. 138-143] объективная оценка научной общественностью «великих замыслов» и «небывалых усилий» соискателя ДВГУПС Милой по разработке третьего пункта «новизны проведенного исследования» (третьего «выносимого на защиту основного положения»), выраженная в четырех отрицательных отзывах на ее пресловутую «диссертацию высококвалифицированных сотрудников ДВГУПС, СПбГУГА, ЦСР ГА и АТиСО (Москва) и констатирующая полную абсурдность этого безграмотно пункта «новизны». С такой оценкой остается только согласиться [2];

- во-вторых, как отмечалось в настоящей работе выше (в подразделе 2.3), в монографиях [13] сообщалось, что 20 марта 2012 года защита диссертации Милой А.В. в диссертационном совете ДМ 223.005.02 при МГУ им. Г.И. Невельского не состоялась, якобы, по причине "болезни соискателя". Вместе с тем, в автореферате и диссертации Милой в целом, которые должны были представлены для защиты 20 марта 2012 года, никакие «показатели экономической эффективности управления АМИП и показатели результативности создания ГЧП в АМИП» не были вообще упомянуты, не говоря уже о представлении каких-либо соответствующих таблиц и каких-либо комментарий к ним. И об этом Куренков и др. были тогда прекрасно осведомлены как составители «отзыва ведущей организации» МИИТ по диссертации Милой;

- в-третьих, а уже 13 апреля 2012 года был разослан новый автореферат диссертации Милой, подписанный в печать 10 апреля 2012 года [1-3]. Так вот, в этом автореферате Милой (как в новом варианте еe диссертации), вдруг, появились «показатели экономической эффективности управления инфраструктурой АМИП» и «показатели, характеризующие социальноэкономическую эффективность $\quad u$ результативность создания ГЧП в АМИП». То есть практически в 20-дневный промежуток времени (с 20 марта по 10 апреля 2012 года) Милая 
успела «сляпать» весьма сомнительные «показатели», вставить их в не менее сомнительные «таблицы», снабдить их маловразумительными комментариями и говолотяпски разместить все это в автореферате и диссертации. При этом вполне очевидно, что не стоит полностью отрицать либо непосредственное участие в этой противоправной афере, либо деликтно-рисковое соглашательство с ней ответственных руководящих сотрудников МИИТ Куренкова и др.;

в-четвертых, если внимательно приглядеться к большинству перечисленных в таблице 4 автореферата и таблице 3.4 диссертации и, по мнению Милой, «традиционно рассчитываемых для оценки» «показателей экономической эффективности управления инфраструктурой АМИП» (то есть давно известных и тривиальных показателей оценки эффективности любого «управления»), то оказывается [2], что это большинство на самом деле относится не к обобщенной оценке «экономической эффективности управления» в целом, а к оценке «экономической эффективности» практической реализации «программ по совершенствованию управления инфраструктурой АМИП» (причем, с учетом даже непонятного для рыночной экономики «отраслевого нормативного коэффициента эффективности»). Однако, составители «отзыва ведущей организации халатно или специально не заметили этого. Налицо - еще один факт вранья, халтуры и невежества Куренкова и др.;

- в-пятых, как было установлено в подразделе 4.2 монографии [2, с. 157-209], таблицы 4 и 5 автореферата и таблицы 3.4 и 3.5 диссертации Милой и комментарии к ним наполнены многочисленными глупостями и нелепицами, что относительно северных аэропортов МВЛ Хабаровского края выглядит полнейшей белибердой (абракадаброй). Все это свидетельствует о том, что указанные «показатели» были авантюрно и жульнически вставлены в диссертацию Милой лишь для того, чтобы, как говорят в народе, «заполнить поляну» автореферата «фундаментальными» (на самом деле, тривиальными) инструментами измерения «экономической эффективности управления инфраструктурой «АМИП», придать ему и всей диссертации призрачно-абстрактную видимость научно-практической ценности и, тем самым, нагло «надуть» экспертов и других представителей научной общественности. На что Куренков др. собственно [1-3] и «клюнули» либо из-за своей ужасающей некомпетентности, либо постыдной беспринципности;

- в-шестых, содержание монографий $[1,3]$ и всего раздела 4 работы [13] позволяет констатировать, что никакого хоть мало-мальски приемлемого «предложенного варианта структуры управления аэропортовой инфраструктурой для КГУП «Хабаровские авиалинии» и никаких научно-практических доказательств «подтверждения экономической и социальной эффективности» этого «варианта» в пресловутом «диссертационном исследовании» небезызвестного «молодого ученого» Милой вообще не представлено, да и не могло быть представлено в силу нелепости и невежественности ее соответствующих авантюрных попыток и иллюстрирующих их безграмотных фрагментов «фундаментального научного труда» данного соискателя ДВГУПС. Налицо - наглое и невежественное вранье Милой;

- в-седьмых, ведь уже в 2014 году [2] было подписано распоряжение Правительства РФ о создании федерального казенного предприятия «Аэропорты Дальнего Востока», куда вошли и аэропорты МВЛ Хабаровского края: «Охотск», «Богородское», «Чумикан», «Херпучи», «Аян». Именно в связи с этим, по свидетельству заместителя министра промышленности Хабаровского края С. Воронина («Тихоокеанская звезда». - 2014. - 28 июня), появилась возможность сохранить и модернизировать аэропорты в отдаленных поселках, поскольку «теперь, с появлением ФКП, средства на это будут поступать из федерального бюджета (до 2018 года край получит 6 млрд. рублей)». Это означало полное фиаско бредового способа «управления инфраструктурой аэропортов малой интенсивности полетов», «сляпанного» Милой при помощи плагиата (литературного воровства) и отраженного «в кривом зеркале» ее пресловутого «диссертационного исследования»;

- в-восьмых, следует констатировать [2], что вся изложенная лично автором в процессе выполнения «диссертационной работы» формулировка третьего «выносимого на защиту основного положения диссертационного исследования» (третьей «научной новизны»), которую соискатель ДВГУПС Милая привела в автореферате (стр. 7 и 16) и диссертации (стр. 9-20), представляет собой, не что иное, как самый неприглядный образчик несусветной глупости, неграмотно описанной и густо замешанной на вранье. То есть весьма смехотворной глупостью, которая в наибольшей степени должна раздражать российское научное сообщество (и не только российское);

- в-девятых, таким образом, налицо очередные проявления невежества, вранья и плагиата (литературного воровства) соискателем Милой, а также не только некомпетентности, но и вопиющей беспринципности и профессиональной экспертной непригодности, представителей ведущей организации (МИИТ) Куренкова и др. Ведь именно последние дали положительный отзыв на диссертацию Милой, не отметив в нем вскрытые факты в монографиях [1-3] такого невежества, вранья и плагиата.

\section{Литература}

1. Леонтьев Р.Г. Диссертация об аэропортах МВЛ: кражи идей, вранье о результатах, невежество утверждений (как не надо представлять общую характеристику диссертации): монография / 
Р.Г. Леонтьев. - Владивосток: Дальневост. федерал. ун-т, 2017. - 190 с.

2. Леонтьев Р.Г. Завиральные и невежественные байки из «диссертации» об аэропортах МВЛ: образчики профанации науки (как не надо представлять защищаемые положения диссертации): монография / Р.Г. Леонтьев. Владивосток: Дальневост. федерал. ун-т, 2017. $211 \mathrm{c}$.

3. Леонтьев, Р.Г. Диссертация о малых аэропортах и нелегитимные заимствования из материалов краевого правительства (как не надо писать диссертацию): монография / Р.Г. Леонтьев. - Владивосток: Дальневост. федерал. ун-т, 2016. - 156 с.

4. Леонтьев Р.Г. Невежественная аргументация при анализе «аэропортовой инфраструктуры в условиях малой интенсивности полетов» (как не надо публиковать статью в рецензируемом журнале) // Вестник транспорта. - 2017. - № 2. - С. 34-41.

5. Леонтьев Р.Г. Невежественная аргументация при анализе «аэропортовой инфраструктуры в условиях малой интенсивности полетов» (как не надо публиковать статью в рецензируемом журнале) (окончание) // Вестник транспорта. 2017. - № 3. - С. 39-43.

6. Леонтьев Р.Г. Супермалая ценность «малой интенсивности полетов» (уроки формулирования и экспертизы актуальности темы диссертации) // Вестник транспорта. - 2014. - № 7. - С. 3-8.
7. Леонтьев Р.Г. Супермалая ценность «малой интенсивности полетов» (уроки формулирования и экспертизы актуальности темы диссертации) (окончание) // Вестник транспорта. - 2014. - № 8. C. 25-32.

8. Азимов Л. Перспективная модель аэропорта как основа развития бизнеса (Источник: журнал "Аэропорт - партнер"). - Сайт ЗАО ПАКК 2003 http://transport.pacc.ru

9. Фурщик М.А., Ляшева Н.В. Аэропорты Хабаровского края // Транспорт Российской Федерации. - 2010. - № 4(29). - С. 15-17.

10. Воздушный кодекс Российской Федерации. - М.: Ось-89, 2007. - 64 с.

11. Варнавский В.Г. Партнерство государства и частного сектора: формы, проекты, риски: научное издание. - М.: Наука, 2005. - 315 с.

12. Технико-экономическое обоснование создания Федерального казенного предприятия по аэропортовой деятельности на базе северных аэропортов Хабаровского края. - Хабаровск: Министерство промышленности, транспорта и связи Хабаровского края, 2009. - 190 с.

13. Программа развития и модернизации аэропортов Николаевск-на-Амуре, Охотск, Аян, Чумикан, Богородское, Херпучи на период до 2029 года. - Хабаровск: Министерство промышленности, транспорта и связи Хабаровского края, 2009. - 162 с.

\section{ФАЛЬШИВЫЕ НОТКИ «ЗАМЕЧАНИЙ И НЕДОСТАТКОВ» ИССЛЕДОВАНИЯ} ОБ АЭРОПОРТАХ МВЛ

Леонтьев Рудольф Георгиевич д-р экон. наук, профессор, почетный работник высшего профессионального образования РФ, главный научный сотрудник ВЦ ДВО РАН, г. Хабаровск, Российская Федераичя

\section{FALSE NOTES "COMMENTS AND DEFECTS" RESEARCH ABOUT MVL AIRPORTS}

Leontyev R.G. Computer center of the Far East office Russian Academy of Sciences Khabarovsk, Russia

\section{АННОТАЦИЯ}

DOI: 10.31618/ESU.2413-9335.2020.4.76.918

В статье рассмотрена представленная в отзыве ведущей организации нелепая попытка его продуцентов сформулировать фальшивые замечания и недостатки диссертации о менеджменте аэропортами местных воздушных линий. Доказано, что эта попытка сотрудников МИИТ вызвана их халатным незнанием текста диссертации, а ее (попытки) результатом стала фальсифицированное (то есть на самом деле несуществующее в действительности) содержимое этой научно-квалификационной работы.

\section{ANNOTATION}

The article examines the absurd attempt of its producers, presented in the review of the leading organization, to formulate fake remarks and shortcomings of the dissertation on the management of local airlines. It is proved that this attempt of MIIT employees was caused by their negligent ignorance of the text of the dissertation, and its (attempts) resulted in a falsified (that is, in fact, non-existent in reality) content of this scientific qualification work.

Ключевые слова: Менеджмент аэропортами, местные воздушные линии (МВЛ), государственная научная аттестация, диссертация, отзыв ведущей организации, замечания и недостатки диссертационного исследования.

Key words: Airport management, local airlines (МВЛ), state scientific certification, dissertation, review of the leading organization, remarks and shortcomings of dissertation research. 